\title{
THE APPLICATION OF THE GENETIC ALGORITHM TO THE NUMERICAL SIMULATION IN SHEET METAL FORMING
}

\author{
Jingjing $\mathrm{Xu}$, Changdong Li, Yimin $\mathrm{Wu}$, Wei Huang \\ 'School of Mechanical Engineering, Shanghai University, China; Email: \\ xujingiing1125@yahoo.com.cn
}

Abstract: This study presents a genetic algorithm GA adopted for recognizing the material parameters with the nonlinear relation in the sheet metal forming. Firstly the nonlinear regression model is established for the parameters estimation. Then based on the material tensile test the parameters estimation is finished by GA and the least square method LS. At last GA is applied for recognizing the material model parameters and the numerical simulation is finished in the V-shape sheet metal forming.

Key words: Genetic Algorithm, Numerical Simulation, Parameter Recognition, Finite Element Method, Nonlinear Material Model.

\section{INTRODUCTION}

The accurate input of the material model parameters is highly important for the numerical simulation in the sheet metal forming, and the parameters recognition of the material model is a complex combinatorial optimization problem. Frequently the material model is so complicated that it is difficult to get the optimum model parameters with conventional methods such as direct search method, Hoole-Jeeves method, and Gauss-Newton method etc. ${ }^{1}$ As a probabilistic search technique the genetic algorithm GA base on the principles of biological evolution, which a biological organism evolves to more fully adapt to its environment, GA becomes a powerful analytical tool to solve an array of constrained and combinatorial optimization problems rapidly. ${ }^{2-6}$ Now GA is less applied for the field of the numerical simulation. In this paper GA is applied to deal with the optimization problem of the parameters recognition by using propagation, crossover and mutation

This project is supported by the Ford-China Research and Development Foundation under the grant No.9716214.

Please use the following format when citing this chapter:

$\mathrm{Xu}$, Jingjing, Li, Changdong, Wu, Yimin, Huang, Wei, 2006, in International Federation for Information Processing (IFIP), Volume 207, Knowledge Enterprise: Intelligent Strategies In Product Design, Manufacturing, and Management, eds. K. Wang, Kovacs G., Wozny M., Fang M., (Boston: Springer), pp. 755-760. 
operation. Firstly based on the material tensile data the parameters estimation is finished by GA and the least square method LS, and the compared results show that GA is better than the result of LS. Then the gotten model parameters are used for the numerical simulation in the Vshape sheet metal forming. ${ }^{7,8}$

\section{PROBLEM DESCRIPTION FOR PARAMETERS RECOGNITION OF THE MATERIAL MODEL}

The material parameters are where the shoe pinches for the numerical simulation in the sheet metal forming, and the material model is nonlinear elastic-plastic material. In this paper two material models are adopted. The material model 1 expresses the elastic-plastic behavior with a power exponent relationship, and the yield stress function is shown as equation (1)

$$
\sigma_{y}=k \varepsilon^{m} \dot{\varepsilon}^{n}
$$

Where, $k$ is strength coefficient, $m$ is hardening index, $n$ is strain rate sensitivity coefficient.

The material model 2 provides the elastic-plastic behavior with isotropic hardening and has a power law constitutive relationship, which includes the Cowper-Symonds multiplier to account for strain rate as equation (2).

$$
\sigma_{y}=\left[1+\left(\frac{\dot{\varepsilon}}{c}\right)^{\frac{1}{p}}\right] k \varepsilon^{n}
$$

Where $\sigma_{y}$ is yield stress, $\dot{\varepsilon}$ is strain rate, $\varepsilon$ is strain, $c, p$ are CowperSymonds strain rate coefficient, $k$ is strength coefficient, $n$ is hardening index.

The nonlinear regression method is used for the parameters estimation of the nonlinear function. Based on two material models the nonlinear regression model can be expressed as follows:

$$
\left\{\begin{array}{c}
\sigma_{y}=\mathrm{f}\left(\varepsilon, \varepsilon^{\cdot}, \theta\right)+e \\
e \sim \mathrm{N}(0, \sigma 2)
\end{array}\right.
$$

Where $\theta$ respectively express the parameters $k, m, n$ in equation (1) and the parameters $c, p, k, n$ in equation (2), $f\left(\varepsilon_{i}, \dot{\varepsilon}_{i}, \hat{\theta}\right)$ is the nonlinear function, and error $e$ yield to the standard normal distribution function, and the value $\left\{\left(\varepsilon_{i}, \dot{\varepsilon}_{i}, \sigma_{y i}\right), i=1,2, \ldots, \mathrm{n}\right\}$ can be gotten by the material tensile 
test data, now the nonlinear parameters recognition is means that how to get the estimation parameters $\hat{\theta}$ to satisfy the formula (4) for any value $\theta$.

$$
\begin{aligned}
& f(\hat{\theta}) \leq f(\theta) \\
& f(\theta)=\sum_{i=1}^{n}\left[\sigma_{y_{i}}-\mathrm{f}\left(\varepsilon_{i}, \dot{\varepsilon}, \theta\right)\right]^{2}
\end{aligned}
$$

\section{MATERIAL PARAMETERS ESTIMATION}

It is necessary to build the nonlinear elastic-plastic material model for the process simulation in the sheet metal forming, so the unilateral tensile test of the thin steel plate is finished by ZWICK tensile machine at various speed, and the data of true stress $s s$, true strain $s n$ and strain rate $s n r$ are gotten and shown as table.1.

Table 1. True stress ss (MPa), true strain $s n\left(\times 10^{-6}\right)$ and strain rate $s n r\left(\times 10^{-4} / \mathrm{s}\right)$ data

\begin{tabular}{llllllllllll}
\hline snr1 & sn1 & ss1 & snr2 & sn2 & ss2 & snr3 & sn3 & ss3 & snr4 & sn4 & ss4 \\
\hline 3 & 0.06 & 120 & 3 & 0.06 & 143 & 3 & 0.06 & 153 & 3 & 0.06 & 147 \\
3 & 0.10 & 199 & 3 & 0.10 & 222 & 3 & 0.10 & 229 & 3 & 0.10 & 219 \\
12 & 0.50 & 312 & 15 & 0.50 & 315 & 13 & 0.51 & 312 & 543 & 0.58 & 337 \\
24 & 1.01 & 329 & 30 & 1.01 & 326 & 27 & 1.00 & 327 & 561 & 1.51 & 357 \\
21 & 2.00 & 350 & 47 & 2.01 & 351 & 30 & 1.50 & 341 & 532 & 2.59 & 378 \\
20 & 4.00 & 379 & 63 & 4.01 & 386 & 58 & 3.50 & 380 & 527 & 4.60 & 406 \\
17 & 6.00 & 399 & 85 & 6.01 & 409 & 74 & 5.51 & 403 & 556 & 6.52 & 423 \\
16 & 10 & 426 & 114 & 10 & 439 & 115 & 9.51 & 433 & 540 & 10.6 & 449 \\
13 & 11 & 431 & 113 & 11 & 446 & 124 & 10.5 & 439 & 529 & 11.5 & 454 \\
8 & 12 & 435 & 112 & 12 & 451 & 128 & 11.5 & 444 & 508 & 12.6 & 458 \\
176 & 15 & 461 & 116 & 13 & 456 & 138 & 12.5 & 449 & 471 & 13.6 & 462 \\
264 & 18.5 & 475 & 324 & 20 & 479 & 392 & 21.5 & 481 & 386 & 23.1 & 473 \\
\hline
\end{tabular}

Confirming the GA essential points is necessary before the genetic code is finished by program language $\mathrm{VC}++6.0$.

GA code is a combination result of the code scheme, strategy selection, and genetic arithmetic operators. In the code scheme the real number encoding is selected, and the standard fitness function is applied for the measuring the fitness of the population. The original fitness function is transferred into the maximal standard $f i t(\theta)$ measure and the value of fitness always is not less than zero. According to the formula (4) the original fitness function estimation is shown as follows.

$$
f i t(\hat{\theta})=\sum_{i=1}^{n}\left[\sigma_{y i}-f\left(\varepsilon_{i}, \dot{\varepsilon}_{i}, \hat{\theta}\right)\right]^{2}
$$


Where, $\left.\left(\varepsilon_{i}, \dot{\varepsilon}_{i}, \sigma_{y i}\right), i=1,2 \ldots n\right)$ is the value of the strain, strain rate and yield stress at $i$ point in the tensile test, $\hat{\theta}$ is parameters estimate, and $f\left(\varepsilon_{i}, \dot{\varepsilon}_{i}, \hat{\theta}\right)$ is the yield stress estimation of the material model as equation (1) and equation (2).

Different strategy selection will produce the different selection pressure. The convergent speed of the high pressure is faster than the speed of the low pressure in the genetic algorithm. Here, the linear ranking selection is adopted; the selection probability $p_{i}$ is confirmed by the sort of the individual fitness value in population as $p_{i}=2 *(i+1) / N /(N+1)$. Where, $N$ is the population number, and $i$ is the selected number from 1 to $N$. based on the select probability $p_{i}$ a random number $r$ between 0 and $l$ is generated, and if the equation, $p_{0}+p_{1}+\quad+p_{i-1}<r \leq p_{1}+p_{2}+\quad p_{i}$, is satisfied by the roulette wheel selection the individual $i$ is gained.

The control parameters consist of the population number $N=50$, the maximal iterative number gen $=1000$, and the probability of the genetic operations such as propagation probability $p_{r}=0.1$, crossover probability $p_{c}=0.9$, mutation probability $p_{m}=0.15$.

The global correlation coefficient $r$ is used for the estimate the results of the recognition parameters as equation (6), and the meanings of the other symbol in the equation are as before.

$$
r=\sqrt{1-\frac{\sum_{i=1}^{n}\left(\sigma_{y i}-f(\varepsilon, \dot{\varepsilon}, \hat{\theta})\right)^{2}}{\sum_{i=1}^{n}\left(\sigma_{y i}-\frac{1}{N} \sum_{i=1}^{N} \sigma_{y i}\right)^{2}}}
$$

According the test data, the nonlinear model parameters is estimated by GA and the estimated result is compared with the result of LS method, and the compared results are shown as table 2 .

Table 2.The identified parameters of the material model 1 by using GA and PLS

\begin{tabular}{lllll}
\hline method & $\mathrm{k}(\mathrm{MPa})$ & $\mathrm{m}$ & $\mathrm{n}$ & $\mathrm{r}$ \\
\hline LS & 609.7 & 0.1196 & 0.0133 & 0.9975 \\
GA & 609 & 0.1197 & 0.0131 & 0.999855 \\
\hline
\end{tabular}

Table 2 shows that two methods have the same results, but the value of the correlation coefficient shows that the genetic algorithm has the better precision. Using LS method can't identify the model parameters of the material model 2, so GA program is applied for the parameters estimate as table 3. Based on the stress, strain and strain rate data in table 1, the parameters of the material model 2 are identified by GA code. 

in Sheet Metal Forming

Table 3. The parameters of the material model 2 by GA

\begin{tabular}{llllll}
\hline Method & $\mathrm{C}$ & $\mathrm{P}$ & $\mathrm{k}(\mathrm{MPa})$ & $\mathrm{n}$ & $\mathrm{r}$ \\
\hline GA & 0.062 & 46.5 & 300 & 0.13 & 0.9973 \\
\hline
\end{tabular}

Table. 3 shows that using GA the correlation coefficient is highly at 0.99 . Subsequently the gotten accurate parameters can input the finite element model in the sheet metal forming, and the numerical simulation can be finished.

\section{NUMERICAL SIMULATION OF V-SHAPE PART}

Now the forming process of the V-shape part in the sheet metal forming with the $800 \mathrm{~mm} / \mathrm{min}$ punch speed is simulated by finite element method. The process simulation is presented by ANSYS/LS DYNA software. The sheet metal material is tinned steel, the punch and die material is $45 \#$ steel, the material model 2 is adopted, and the other input parameters of the finite element model are shown as table 4.

Table 4. The input parameters of the finite element model

\begin{tabular}{|c|c|c|c|c|c|c|}
\hline $\begin{array}{l}\text { Punch } \\
\text { density } \rho \\
\left(\mathrm{kg} / \mathrm{m}^{3}\right)\end{array}$ & $\begin{array}{l}\text { Punch elastic } \\
\text { modul } E \\
(\mathrm{MPa})\end{array}$ & $\begin{array}{l}\text { Punch } \\
\text { Poisson } \\
\text { rate } \mu\end{array}$ & $\begin{array}{l}\text { Plate } \\
\text { thickness } \\
t(\mathrm{~mm})\end{array}$ & $\begin{array}{l}\text { Plate width } \\
b(\mathrm{~mm})\end{array}$ & $\begin{array}{l}\text { Plate } \\
\text { length } \\
l(\mathrm{~mm})\end{array}$ & $\begin{array}{l}\text { Pressing } \\
\text { length } l p \\
(\mathrm{~mm})\end{array}$ \\
\hline 7850 & 204000 & 0.271 & 0.34 & 25 & 75 & 64 \\
\hline $\begin{array}{l}\text { Die } \\
\text { density } \\
\rho\left(\mathrm{kg} / \mathrm{m}^{3}\right)\end{array}$ & $\begin{array}{l}\text { Die elastic } \\
\text { modul } E \\
(\mathrm{MPa})\end{array}$ & $\begin{array}{l}\text { Die } \\
\text { Poisson } \\
\text { rate } \mu\end{array}$ & $\begin{array}{l}\text { Punch } \\
\text { radius } R t \\
(\mathrm{~mm})\end{array}$ & $\begin{array}{l}\text { Die radius } \\
R b(\mathrm{~mm})\end{array}$ & $\begin{array}{l}\text { Stoke } S \\
(\mathrm{~mm})\end{array}$ & $\begin{array}{l}\text { Pressing } \\
\text { force } P \\
(\mathrm{kgf})\end{array}$ \\
\hline 7820 & 207000 & 0.29 & 2 & 5 & 43 & 3.968 \\
\hline
\end{tabular}

Based on the geometry shape and loading properties the global model is symmetry structure, so the finite element model is only built $1 / 4$. During the calculation the four-node shell element is selected with Belytschkl-Leriathan element algorithm. The symmetrical constrains are applied to the symmetry boundary of the V-shape part, and the interface friction is deal with the various dynamic and static behavior. The punch speed is alterable virtual speed in order to reduce the calculation time, and the die is fixed, and the simulation forming time is the stop time when the trip is achieved. After the forming phase the springback simulation use the implicit program, and the explicit element is transferred into the implicit element type, and the material type is becoming the linear elastic material. The original structure is the last step shape after the finishing of the explicit calculation. At the same time, the die is moved and the stress status is kept. The symmetrical constrains are loaded, the structural big displacement behavior is considered, and the 
springback simulation is finished. The finite element model of the V-shape part and the simulation result is shown as Fig.1.
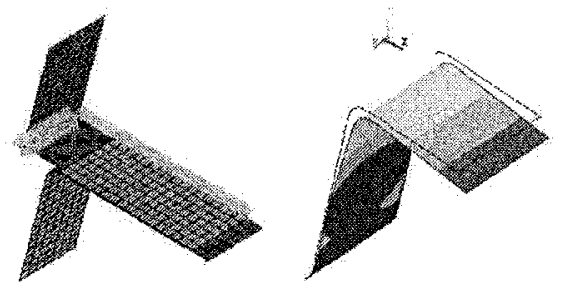

Figure 1. The finite element model and simulation result

\section{CONCLUSION}

1) The genetic algorithm using the real number encoding, using the standard fitness function to describe the fitness of nonlinear material model, through the propagation, crossover and mutation operation the accurate material parameters can be gotten. Comparing with the least square method, the genetic algorithm is simple and flexible and less constrained, and it is more adapted to deal with complicated model parameters with nonlinear material behavior.

2) The genetic algorithm provides a new tool for forming and springback simulation in the sheet metal forming, the use of genetic algorithms to better design and produce reliable products of high quality, and a new approach is achieved for the complicated parameters input in finite element calculation.

\section{REFERENCE}

1. Nash J. C. and Walker Smith M., Nonlinear Parameter Estimation, Marcel Dekker Inc., New York,Basel, 1987

2. Buckles B. P. and Perry F. E., Genetic Algorithms, IEEE Computer Society Press. Los Alamitos,CA, 1992

3. Galletly J. E., (1992), An Overview of Genetic Algorithms, Kybernetics, 21(6), pp.26-30,

4. Angeline P.J, Reynolds R.G., (Eds.), Proc.of the $6^{\text {th }}$ Int'l Conf. On Evolutionary Programming (EP'97), Lecture Notes in Computer Science, NO.1213, Springer-Verlag, 1997

5. Srinivas M. and Patnaik L.M., , Genetic Algorithms: a Survey, Computer, June, pp.1726,1994

6. Pan Zhengjun etc., Evolution Algorithm, Qinghua University Press,2000.

7. LS-DYNA Keyword User's Manual, , Livemore Software Technology Corporation ,1999

8. ANSYS/LS DYNA Basic Algorithm and Using Method, (2000), USA ANSYS LTD. 